\title{
РЕЦЕНЗИЯ НА КНИГУ: Voskressenski, A.D. Non-Western Theories of International Relations: Conceptualizing World Regional Studies. Palgrave Macmillan, 2017. - 271 p.
}

\section{Е.Н. Грачиков}

МГУ имени М.В. Ломоносова, Москва, Россия

Профессор А.Д. Воскресенский - известный российский ученый, синолог, пожалуй, один из немногих, кто осмысление российско-китайских отношений возвел в разряд крупных теоретических обобщений («концепция многофакторного равновесия» [Воскресенский 1999]) и собственных методологических подходов («метод сфокусированного структурированного сравнения» [Воскресенский 2004]). Последние 15 лет Воскресенский посвятил пространственно-аналитической концепции сравнительного анализа политических систем Востока [Voskressenski 2006; Воскресенский, 2007], мировому комплексному регионоведению и незападной теории международных отношений [Воскресенский 2013].

Новая монография А.Д. Воскресенского «Незападные теории международных отношений: концептуализация мировых региональных исследований» стала результатом изысканий ученого последних лет и посвящена теоретическому осмыслению роли (глобальных, макро-) регионов в (незападных) международных отношениях. Автор дает логическое обоснование эволюции мировой системы и связывает новую стадию развития с вовлечением «не запада» в этот процесс, но предупреждает, что мы живем в условиях «множественной модернизации» (multiple modernities) и надеяться на универсальную применимость западных или незападных теорий является иллюзией. Проведя анализ основных концепций взаимосвязи между экономической и политической модернизацией, автор делает вывод о важности социально-политического подхода для объяснения эволюции политической карты современного мира. Он утверждает, что западные теории международных отношений (ТМО) упускают «пространство» в качестве объекта измерения, которое является главным в теоретико-прикладном анализе мировых региональных исследований, и предлагает его как потенциальный объяснительный формат для незападных ТМО. Регионализация, по мнению автора, исходит из существования различных типов регионов, что требует согласования теоретических и практических аспектов региональной трансформации.

Интерес представляет изложенный во введении методологический инструментарий, который можно отнести к социологии международных отношений, поскольку речь идет о международном и региональном обществах в системе глобальных отношений (system of global relations), и, конкретно, о функциональной и структурной дифференциации, предложенной Никласом Луманом в теории диф- 
ференциации [Луман 2009], и принятой в последнее время в качестве аналитического формата при исследовании проблем мировой политики [Bringing Sociology 2013]. Следуя логике Лумана и соглашаясь с Аппадураем (Appadurai) о существовании различных культурных ландшафтов, автор утверждает, что социально сконструированная дифференциация основывается на объективно существующей структурной дифференциации между обществами различных типов (западных/незападных). Для объяснения региональной специфики гетерогенизации/гомогенизации любому исследователю сначала необходимо уяснить различия, укорененные в объективно существующей дифференциации социальных структур, так же, как и тех, которые были социально сконструированы. В международных отношениях политикам, дипломатам или исследователям приходится иметь дело с дифференциацией обоих типов, как внутри, так и вне государств-наций.

Данное исследование также можно рассматривать с позиций классического конструктивизма, где естественным выглядело бы использование «теории отношений» процессного конструктивизма видного китайского ученого Цинь Яцина [Qin Yaqing 2009; 2012, 2016], упоминаемого в тексте, который изучает международное общество (в данном случае глобальное и макрорегиональные) как процесс, - термин, неоднократно встречающийся в монографии в виде «processes», «global processes», «local processes», «world processes», «national process», «sociopolitical processes» и «process logic». «Теория отношений» и процессный подход в китайской ТМО представляют наиболее влиятельные и обсуждаемые концепции, основанные на национальных политических и философских традициях [Cao Dejun 2017].

Авторский исследовательский подход заключается в расширении де-вестернизированного (или внекультурного/исторического) формата анализа международных отношений, который позволяет включить в себя как структурные, так и культурные/исторические различия между регионами и национальными государствами в качестве их главных составных частей, а также других акторов, вместо специального конструирования какого-то сегмента незападных теорий (но не исключая полностью подобной возможности). Такой подход исходит из «неравного характера международного политического и экономического пространства» и основан на убеждении, что концептуализация в существующих классических дисциплинах международных отношений (политическая теория, международная политическая экономия и сравнительная политология) не может больше объяснить в полной мере многие процессы, вызванные тесными и более интерактивными связями между локальным, региональным и глобальным измерениями.

В этом труде использован новый интегрированный подход анализа социально-экономических и культурно-политических пространств, который устанавливает расстояния и дифференциации в формировании, функционировании и развитии «глобальных политических отношений». Такой подход позволил использовать максимально необходимое количество переменных, которые оказывают влияние на каузальные параметры, связанные с историческим результатом. Понимая, что количество переменных может быть ограничено средствами формализованного и неформализованного факторального анализа (factor analysis), фокус исследования был направлен на стратегию междисциплинарного изучения с использова- 
нием качественных и количественных методов, в которых гипотезы направляются объяснительными средствами, определяемыми историками, в то время как конструирование научных гипотез должно быть структурировано на основе методов социальных наук.

Монография состоит из 10 глав: первая - введение, десятая - заключение. Основная часть работы А.Д. Воскресенского начинается с главы «Вызовы существующей системе международных отношений и как они отображены в литературе по международным отношениям в западном и незападном сегментах», где анализу была подвергнута мировая научная литература: основная повестка европейских и американских исследований, западно-центричные и восточно-центричные подходы, незападная повестка в международной литературе, российские достижения, сравнение российских и китайских концептуализаций незападной реальности. По мнению автора, главная повестка европейских исследований обычно включает процесс европейской интеграции и влиянии ее различных аспектов на каждую страну и Евросоюз в целом, американских - концентрируется на роли США в создании предпочтительных зон и сфер своей глобальной и региональной политики. Объединенные на общих ценностях межатлантической истории, эти два макрорегиона отражают взгляд на мир с точки зрения будущего евро-атлантического сообщества. Поскольку эти регионы тесно связаны с распределением/перераспределением власти в глобальной системе и в международной управленческой структуре, их исследования касаются сферы международной политики и политико-экономического анализа, а также использования собственной отличительной методологии формулирования (problem-posing) и решения проблемы (problem-solving), определяемые спецификой международного анархического общества, направляемого суверенными государствами.

Интерпретация мировой истории Западом и Востоком - «синтетическая политическая экономия» (synthetic political economy), в прогнозировании трендов будущей «синтетической парадигмы» (synthetic paradigm) развития человечества (главные черты которой сейчас только начинают формироваться) представляет западно-центричные и восточно-центричные взгляды на историю, которые исторически ограничены, что не отменяет необходимости анализа дихотомии глобальных макрорегионов (в частности, проблем дихотомии Запада и Востока). Сейчас существуют два вектора концептуализации в мировых и глобальных исследованиях: первый - представляет вероятность появления и развития незападных концепций международных отношений, глобальной политики и сравнительной политологии; второй - будет фокусироваться на других незападных конструктивистских подходах в теоретических построениях глобального и регионального уровней, определенных между универсальными и исключительными регионально/страновыми подходами.

В России, как верно утверждает автор, наряду с подходом об азиатском способе производства, рассматриваемом в марксистской парадигме в работах Л. Васильева, О. Непомнина, Л. Алаева, также развивался взгляд о структурных разли- 
чиях обществ западного и восточного типов. В последние годы, вследствие возрождения российского национализма, фокус в исследованиях сместился на структурную трансформацию международного порядка, связанную с социетальной структурной дифференциацией, международными дебатами о существовании незападных ТМО и возможностью русской ТМО играть незападную роль. Новые российские публикации он группирует в 4 категории: первая - представлена Андреем Макарычевым и Вячеславом Морозовым, которые настаивают на том, что «незападные» теоретические рассуждения строятся на ошибочном допущении бесконечности разнообразия коллективного опыта, которое может быть понято на основе эпистемологического плюрализма; вторая - представлена Татьяной Алексеевой, которая, используя западный конструктивистский подход, делает идентичность зависимой переменной. Таким образом, идентичность приобретает не абстрактную сущность, а становится переменной, которая может быть распространена и изменена конкретными людьми, имеющими собственные системы ценностей и убеждений; третья - представлена группой авторов «Мирового комплексного регионоведения» и некоторыми другими авторами, к коим профессор А.Д. Воскресенский причисляет и себя, которые приняли «метатеоретические рамки» (metatheoretical framework) и «качественный подход среднего уровня» (a qualitative middle-range approach), чтобы объяснить непрерывность и изменения в международных отношениях и, в частности, в региональном измерении; четвертыц представлен работами Андрея Цыганкова и совместными работами Андрея и Павла Цыганковых, которые считают, что русская ТМО должна развиваться как часть незападной ТМО по двум основаниям: а) международные исследования и сами ученые находятся в определенных социальных условиях и отражают культурные предпочтения; и б) международные отношения отражают политические, идеологические и эпистемологические основания.

Рассуждая о переходе от гегемонистской однополярности к многополярному миру в направлении структурной трансформации международной системы, глобального стратегического баланса, профессор А.Д. Воскресенский поднимает такие глобальные и в целом философские вопросы, как рациональность эволюции мировой системы, новый грядущий период в мировом развитии и незападное движение, рассматривает главные гипотезы о связях между экономической и политической модернизацией, важность концепта социально-политического подхода, эволюцию системы социального и политического порядка, формирование политической карты современного мира. На основе глубокого анализа широкого круга источников делает вывод, что меркантильное поведение «победителей» (Запад) в конце XIX и нулевых годах XXI в. привело к появлению конструктивного, деконструктивного и даже агрессивного национализма в незападном секторе мирового пространства. В комплексном глобальном политическом процессе и глобальном пространстве социальных наук роль Востока не нашла релевантного отражения. Поэтому в глобальных социальных науках возникает перспектива для международных мировых региональных исследований в качестве субдисциплины 
международных отношений, основанной на методе политико-экономического анализа региональных субсистем и глобальных регионов.

Для западных исследователей (книга вышла на английском языке и в первую очередь обращена к англоговорящей аудитории) будет важна данная в монографии оценка теории незападных международных отношений и попыткам дальнейшей концептуализации незападной реальности, методологических проблем и контекста повестки мировых региональных исследований, а также, что упускается в западных теориях международных отношений - пространство, как ключевое измерение в мировых региональных исследованиях, «многослойность» пространственно-временной категории в современных международных отношениях. В двух главах автор обращается к исследованию проблемы изменения пространства в макрорегиональном измерении (новые пространственные акторы, различные типы регионов, соотношение между теоретическими и практическими аспектами региональных трансформаций) и дифференциации в мировом пространстве и ее последствий для концептуализации де-вестернизированных международных отношений, где затрагиваются вопросы структурной дифференциации мирового пространства, дифференциации в геопространствнном измерении, региональные субсистемы, соотношение дифференциации и фрагментации.

Важными остаются проблема интеграции пространства в комплексную глокальность, на которую в исследовании обращено особое внимание, поскольку требуются разъяснения таких дефиниций, как местоположение (locality) и определение местонахождения (location), и связанный с этим анализ взаимоотношений между окружающей средой и социумом, мировой культурно-цивилизационной системой и региональными культурно-цивилизационными комплексами, а также политикогеографическая эволюция государств и регионов, гуманитарных систем и ландшафтов. В результате в книге формируются новые обобщающие теоретические понятия - пространство глобальных регионов и региональных субсистем, совмещающих множественные модерности, где исследуются историческая трансформация международной системы, интеграция мирового пространства и формирование глобальных регионов, суть и формы «Восточного Возрождения» и трансформация всего мира.

В конце своего исследования профессор А.Д. Воскресенский приходит к выводу (приведенному здесь в очень сжатой и упрощенной формуле), что практическими принципами незападного видения мира могут быть: выбор модели открытого, эгоцентричного регионального развития, которая включает собственную модель модернизации; переход на кросс-региональное сотрудничество, которое приведет к изменению мирового порядка с более справедливой и взаимовыгодной структурой; подобная модель образует прогрессивное транснациональное (в дальнейшем, трансрегиональное) политико-экономическое пространство глобального сотрудничества регионов в качестве новых акторов в мировой политике.

Книга профессора А.Д. Воскресенского - это серьезный инновационный теоретический труд, куда вложены результаты многолетних изысканий, в котором 
главным является синтез, синтез методов, подходов, теорий и мировосприятий незападных пространств. Для российских преподавателей факультетов международных отношений и мировой политики - это обязательная литература для использования в учебной и научной деятельности. В России, надо признаться честно, не так много ученых, которые могут не только создавать работы такой теоретической глубины, но и быть востребованы в глобальном пространстве социальных наук. Исследование профессора А.Д. Воскресенского относится к их числу.

\section{БИБЛИОГРАФИЧЕСКИЙ СПИСОК}

Воскресенский А.Д. Китай и Россия в Евразии: Историческая динамика политических взаимовлияний. М.: Муравей; 2004.

Воскресенский А.Д. Мировое комплексное регионоведение и перспективы построения незападной (китаизированной) теории международных отношений // Полис. Политические исследования. 2013. № 6. С. $82-96$.

Воскресенский А.Д. Политические системы и модели демократии на Востоке: Учеб. пособие для студентов вузов. М.: Аспект Пресс; 2007.

Воскресенский А.Д. Россия и Китай: теория и история межгосударственных отношений. М.: Московский общественный научный фонд; ООО «Издательский центр научных и учебных программ»; 1999.

Луман Н. Общество общества. Книга 4: Дифференциация. Пер. с нем. Б. Скуратов. Книга 5: Самоописания. Пер. с нем. А. Антоновский, Б. Скуратов, С. Тимофеева. М.: Логос; 2009.

Bringing Sociology to International Relations. World Politics as Differentiation Theory. Ed. by Mathias Albert, Barry Buzan and Michael Zurn. Cambridge: Cambridge University Press; 2013.

Cao Dejun. Guoji zhengzhi "guanxi lilun": gainian, lujing yu tiaozhan [The Relational Theory of International Politics in Chinese Context: Concepts, Approaches and Challenges] // Shijie jingji yu zhengzhi [World Economics and Politics]. 2017. N 2. P. 36-53. (in Chinese).

Qin Yaqing. Guanxi yu guocheng: zhongguo guoji guanxi lilun de wenhua jiangou [Relations and Process: Cultural Foundations of Chinese IR Theory]. Shanghai: Shanghai renmin chubanshe; 2012. (in Chinese).

Qin Yaqing. Guoji zhengzhi lilun de ji ge jiading [Assumptions for Relational Theory of World Politics] // Shijie jingji yu zhengzhi [World Economics and Politics. 2016. Is. 19 (434). (in Chinese).

Qin Yaqing International Society as a Process: Institutions, Identities, and China's Peaceful Rise // The Chinese Journal of International Politics. 2009. Vol. 3. P. 129-153.

Voskressenski, A. Regional Studies in Russia and Current Methodological Approaches for Social/ Historical/Ideological [Re] construction of International Relations and Regional Integration in Eastern Eurasia. In: Reconstruction and Interaction of Slavic Eurasia and Its Neighboring Worlds, eds. Ieda Osamu and Uyama Tomohiko. Sapporo: Slavic Research Center, Hokkaido University. pp. $3-42$.

Дата поступления статьи: 14.03.2017

Для цитирования: Грачиков Е.Н. Рецензия на книгу: Voskressenski, A.D. Non-Western Theories of International Relations: Conceptualizing World Regional Studies // Вестник Российского университета дружбы народов. Серия: Международные отношения. 2017. Т. 17. № 2. С. 425-431.

Сведения об авторе: Грачиков Евгений Николаевич - канд. полит. наук, доцент факультета политологии МГУ им. М.В. Ломоносова, постоянный член Центра мирового социализма академии общественных наук КНР, приглашенный профессор Института азиатских исследований Хэнаньского университета (e-mail: egrachikov@gmail.com). 


\title{
REVIEW OF THE BOOK: Voskressenski A.D. Non-Western Theories of International Relations: Conceptualizing World Regional Studies. Palgrave Macmillan, 2017. - 271 p.
}

\author{
E.N. Grachikov
}

Moscow State University, Moscow, Russia

\section{REFERENCES}

Bringing Sociology to International Relations. World Politics as Differentiation Theory. Ed. by Mathias Albert, Barry Buzan and Michael Zurn. Cambridge: Cambridge University Press; 2013.

Cao Dejun (2017). Guoji zhengzhi "guanxi lilun": gainian, lujing yu tiaozhan [The Relational Theory of International Politics in Chinese Context: Concepts, Approaches and Challenges]. Shijie jingji yu zhengzhi ["World Economics and Politics], 2, 36-53.

Luman, N. (2009). Society of society. B. 4: Differentsiatsiya. Transl by. B. Skuratov. B. 5: Samoopisaniya. Transl by. A. Antonovskii, B. Skuratov, S. Timofeeva. Moscow: Logos. (in Russ.).

Qin Yaqing (2012). Guanxi yu guocheng: zhongguo guoji guanxi lilun de wenhua jiangou [Relations and Process: Cultural Foundations of Chinese IR Theory]. Shanghai: Shanghai renmin chubanshe.

Qin Yaqing (2016). Guoji zhengzhi lilun de ji ge jiading [Assumptions for Relational Theory of World Politics]. Shijie jingji yu zhengzhi [World Economics and Politics], 19 (434). (in Chinese).

Qin Yaqing (2009). International Society as a Process: Institutions, Identities, and China's Peaceful Rise. The Chinese Journal of International Politics, 3, 129-153.

Voskressenskii, A. D. (2004). China and Russia in Eurasia: Historical Dynamics of Political Interactions. Moscow: Muravei. (in Russ.).

Voskressenskii, A. D. (2007). Political systems and models of democracy in the East. Moscow: Aspekt Press. (in Russ.).

Voskressenski, A. Regional Studies in Russia and Current Methodological Approaches for Social/ Historical/Ideological [Re] construction of International Relations and Regional Integration in Eastern Eurasia. In: Reconstruction and Interaction of Slavic Eurasia and Its Neighboring Worlds, eds. Ieda Osamu and Uyama Tomohiko. Sapporo: Slavic Research Center, Hokkaido University. pp. $3-42$.

Voskressenskii, A. D. (1999). Russia and China: Theory and History of Interstate Relations. Moscow: Moskovskii obshchestvennyi nauchnyi fond; OOO «Izdatel'skii tsentr nauchnykh i uchebnykh programm». (in Russ.).

Voskressenskiǐ, A. D. (2013). World complex regional studies and prospects for building a non-Western (Sinetic) theory of international relations. Polis. Political Studies, 6, 82-96. (in Russ.).

Received: 14.03 .2017

For citations: Grachikov, E.N. (2017). Review of the book: Voskressenski, A.D. Non-Western Theories of International Relations: Conceptualizing World Regional Studies. Vestnik RUDN. International Relations, 17 (2), 425-431.

\footnotetext{
About the author: Grachikov Evgeniy Nikolaevich - PhD in Political Science Associate Professor of the Faculty of Political Science of Moscow State University, permanent member of the Center of World Socialism of the Academy of Social Sciences of PRC, visiting professor of the Institute of Asian Studies, Henan University (e-mail: egrachikov@gmail.com).
} 